\title{
Estudio descriptivo del primer mes de situación de pandemia por COVID-19 en una unidad de diálisis hospitalaria
}

\author{
Patricia Arribas-Cobo, Marian Bernabé-Villena, Elena Herrera-Martín, Isabel Martínez-Dios, Sonia Ruiz-Almería, \\ Pilar Díaz de Argote-Cervera
}

Unidad de Diálisis. Hospital Universitario Infanta Leonor. Madrid. España

Como citar este artículo:

Arribas-Cobo P, Bernabé-Villena M, Herrera-Martín E, Martínez-Dios I, Ruiz-Almería S, Díaz de Argote-Cervera P. Estudio descriptivo del primer mes de situación de pandemia por COVID-19 en una unidad de diálisis hospitalaria.

Enferm Nefrol. 2020 Abr-Jun;23(2):133-47

\section{Resumen}

Los pacientes en diálisis constituyen un grupo de riesgo de sufrir infección por SARS-CoV-2 y posiblemente de tener más complicaciones. Los profesionales sanitarios se han enfrentado a una pandemia sin precedentes y de la que había poca información. El objetivo de este estudio ha sido describir la experiencia del primer mes viviendo la pandemia generada por SARS-CoV-2 en una unidad hospitalaria de hemodiálisis de Madrid, tanto en relación a los pacientes como al personal sanitario. Así mismo, se pretende reflejar las actuaciones sanitarias durante dicho mes.

El total de pacientes en la unidad fue de 90, realizándose la determinación PCR a todos, $37(41,1 \%)$ dieron positivo a COVID-19, de estos $22(59,4 \%)$ eran sintomáticos y $15(40,5 \%)$ eran asintomáticos. De los pacientes positivos, $16(43,2 \%)$ precisaron ingreso hospitalario y $6(16,2 \%)$ fallecieron. Los pacientes fallecidos eran de mayor edad que los supervivientes.

La muestra de profesionales sanitarios fue de 44 , de los que 15 (34\%) presentaron sintomatología. El servicio de Salud Laboral sólo determinó PCR a este grupo, obteniendo 4 profesionales (9\%) PCR positivo, sin embargo tras considerar los criterios clínicos/radiológicos

\section{Correspondencia:}

Patricia Arribas Cobo

e-mail: parribasc@salud.madrid.org un total de 9 profesionales fueron diagnosticados como COVID-19 positivos, requiriendo 1 de ellos ingreso hospitalario.

Conclusiones: se detectó una elevada prevalencia de COVID-19 positivo en los pacientes de la unidad de diálisis, donde destaca el elevado número de pacientes asintomáticos detectados mediante cribado PCR al total de los pacientes. Algunos profesionales presentaron algún tipo de sintomatología correspondiente con clínica COVID-19, pero se detectaron pocos casos con PCR positiva.

PALABRAS CLAVE: pandemia; COVID-19; SARSCoV-2; hemodiálisis; cribado epidemiológico; enfermería.

\section{Descriptive study of the first month of situation of the COVID-19 pandemic in a hospital dialysis unit}

\begin{abstract}
Dialysis patients are at risk group for SARS-CoV-2 infection and possibly have more complications. Healthcare professionals have faced an unprecedented pandemic, for which little information existed. The objective of this study was to describe the experience of a Madrid hospital haemodialysis unit during the first month of the SARS-CoV-2 pandemic, both in relation
\end{abstract}


to patients and healthcare personnel. Likewise, it is intended to report the health actions.

The total number of patients in the unit was 90. In all patients, the PCR test was performed. $37(41.1 \%)$ tested positive for COVID-19, of these $22(59.4 \%)$ were symptomatic and $15(40.5 \%)$ were asymptomatic. of the positive patients, $16(43.2 \%)$ required hospital admission, 6 of whom died (16.2\%). The deceased patients were older than the survivors.

Health professionals were 44, of whom 15 (34\%) had symptoms. The Occupational Health service only performed PCR on the symptomatic group, having 4 professionals (9\%) positive PCR. However, after considering the clinical / radiological criteria, 9 professionals were diagnosed as COVID-19 positive, 1 of them requiring hospital admission.

Conclusions: A high prevalence of positive COVID-19 was detected in patients in the dialysis unit, highlighting the high number of asymptomatic patients detected by PCR screening. Some healthcare professionals presented some type of symptoms corresponding to the COVID-19 disease, however, few cases were detected with positive PCR.

KEYWORDS: pandemic; COVID-19; SARS-CoV-2; haemodialysis; epidemiological screening; nursing.

\section{Introducción}

El 12 de marzo de 2020, la Organización Mundial de la Salud (OMS) considero como pandemia un brote infeccioso causado por el nuevo coronavirus llamado SARS-CoV 2 (COVID-19) puesto que se habían notificado 125.000 casos en 118 países $^{1,2}$. El virus causante de esta pandemia es un coronavirus, denominado coronavirus del síndrome respiratorio grave agudo 2 (Severe Acute Respiratory Syndrome Coronavirus Disease), SARS-CoV-2. Se considera que su origen está en los murciélagos con transmisión a otras especies y posteriormente al humano, principalmente por vía respiratoria. El foco original de la pandemia fue la ciudad de Wuhan, China, exten-

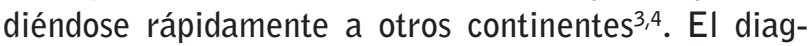
nóstico de laboratorio reside fundamentalmente en la prueba de identificación genómica del virus mediante la reacción en cadena de la polimerasa por transcriptasa reversa de tiempo real (rRT-PCR)².
Actualmente, hay muchas dudas respecto al comportamiento del patógeno aunque recientes estudios muestran que desde etapas iniciales hay una gran carga viral en la orofaringe, lo que aumenta el riesgo de infección durante los periodos de incubación. Se ha estimado un periodo de incubación medio de 5-6 días, con un rango de 1 a 14 días. Los síntomas de la enfermedad en más de un $80 \%$ de los casos son leves (fiebre, tos, expectoración, malestar general), mientras que aproximadamente el $20 \%$ pueden tener manifestaciones clínicas más graves (neumonía y otras complicaciones clínicas) que requieran ingreso hospitalario ${ }^{1-4}$.

La población más vulnerable a la enfermedad COVID-19 son los ancianos y los pacientes con varias patologías como diabetes mellitus, hipertensión y enfermedad cardiovascular siendo probable que presenten una mayor morbimortalidad y requieran soporte respiratorio e ingreso en $\mathrm{UCI}^{2}$.

Los pacientes en diálisis pueden tener alteraciones en la inmunidad por lo que constituyen un grupo de riesgo de sufrir la infección por el SARS-CoV-2 y posiblemente de tener más complicaciones ${ }^{5-6}$. Además presentan connotaciones epidemiológicas relevantes: acuden a un centro médico con regularidad, incluso seis veces por semana, permanecen en él más de 4 horas expuestos a posible contagio y la mayoría acuden al tratamiento en transporte sanitario colectivo. Una vez infectados son una fuente móvil de nuevos contagios dentro del grupo de riesgo. Así, podemos decir que una unidad de diálisis es un lugar de especial consideración ${ }^{7}$.

El Hospital Universitario Infanta Leonor atiende al distrito de Vallecas que, a fecha 16 de abril de 2020, constituye el segundo distrito en incidencia acumulada de COVID-19 de la ciudad de Madrid con 994,39 pacientes infectados por cada 100.000 habitantes $^{8}$.

EI 26 de febrero de 2020 se confirmaron los 2 primeros casos de COVID-19 en la Comunidad de Madrid, contagiados en zonas de riesgo, el 28 de febrero había 5 casos y el día 3 de marzo 56 ( 5 graves $)^{9}$. El primer caso en nuestro hospital se diagnosticó el día 4 de marzo, y el 5 marzo se creó un grupo coordinador. En ese momento la información específica en relación con los pacientes renales 0 en unidades de diálisis era escasa pero una publicación de la zona de Wuhan (China) recogían los casos que habían aparecido en una unidad de diálisis con 230 pacientes y 33 trabajadores con signos de la enfermedad ${ }^{10}$ y la Asociación Americana de Nefrología había publicado una serie de recomendaciones ${ }^{5}$, poste- 
riormente lo hicieron el Ministerio de Sanidad junto con la Sociedad Española de Nefrología y la Sociedad Española de Enfermería Nefrológica ${ }^{11}$, así como documentación específica de la Sociedad Española de Nefrología ${ }^{12}$ y la ERA-EDTA ${ }^{6}$.

El objetivo de este estudio es describir la experiencia de una unidad de hemodiálisis hospitalaria de Madrid durante el primer mes de la pandemia ocasionada por COVID-19.

\section{Material y Método}

\section{Diseño, ámbito y duración del estudio}

Estudio observacional prospectivo que se llevó a cabo en el Hospital Universitario Infanta Leonor de Madrid entre el 3 de marzo y el 8 de abril de 2020.

\section{Población}

Todos los pacientes (90) que constituían el programa de hemodiálisis crónica del centro sin ningún criterio de exclusión.

\section{Variables}

Para su posterior análisis se tuvieron en cuenta las variables definidas en los siguientes apartados:

- Medidas iniciales para evitar la propagación.

- Protocolo de actuación.

- Características de los casos que incluyen los test de detección.

- Cronograma de la evolución.

\section{Procedimiento}

Ante la aparición de un número de casos cada vez mayor, el día 3 de marzo (día 0) el equipo asistencial decide trasladar al centro periférico pacientes y reorganizar turnos con el fin de tener los máximos puestos posibles en la unidad hospitalaria para poder atender a todos los pacientes que requirieran ingreso. En ese momento, el concepto de caso probable era mucho más limitado, dado que tenía que existir historia de viaje a un área con evidencia de transmisión comunitaria, con un contacto estrecho con otro caso probable o confirmado, infecciones respiratorias graves en las que se hubieran descartado otras causas (hasta el 11 de marzo no se declaró Madrid como zona de transmisión comunitaria del SARS-CoV-2).

Basándonos en el documento que se realizó en su momento para gripe $A$, se redactó un protocolo de actua- ción que el 5 de marzo (día 2) trasladamos a gerencia, servicio de medicina preventiva y a los médicos responsables COVID-19. Dicho protocolo incluía:

- Información para los pacientes sobre la infección, prevención y medidas a tomar ante la aparición de síntomas (Anexo 1).

- Manejo básico en hemodiálisis con la creación de un triaje, la separación física para la sesión de paciente infectado/sospechoso y la estructuración de personal y organización de los medios (Anexo 2).

Se contactó con los pacientes de la unidad para que, en la medida de lo posible, se evitara utilizar la ambulancia colectiva, fomentándose el transporte por vehículo propio o por familiares. Para el confinamiento se diseñó una carta/certificado con el nombre del paciente sin especificar turno en previsión de posibles cambios para facilitar también el transporte por vehículo propio o por familiares.

El día 9 de marzo (día 6) un médico fue el primero en causar baja por COVID-19. El día 10 de marzo (día 7) se detecta el primer caso confirmado de COVID-19 entre los pacientes. El día 12 de marzo (día 9) comenzamos a realizar un triaje previo a la sesión de hemodiálisis, realizándose en la consulta más próxima a la sala de espera, que es una zona amplia, donde se procuraba evitar aglomeraciones y se indicaba a los pacientes que mantuvieran una distancia de seguridad entre ellos durante la espera. Inicialmente, el triaje lo hacía un médico y una enfermera ayudados por un técnico en cuidados auxiliares de enfermería (TCAE), aunque posteriormente esto se modificó, llevándose a cabo por una enfermera y un TCAE, avisando al médico ante posibles dudas sobre una posible infección.

Se instó a los pacientes a que se lavaran las manos y el brazo de la fístula antes de salir de casa y nos aseguramos que todo paciente llevara mascarilla desde que salía de su domicilio. En el mismo triaje se procedía al lavado de manos con solución hidroalcohólica. En un documento se recogían: temperatura, síntomas de sospecha, familiares afectados y transporte en el que acudían (vehículo propio o ambulancia colectiva). Si no había sospecha de infección se hacían pasar a la sala de diálisis donde se iban colocando según orden de entrada, manteniendo la separación de 2 metros o más y esperan hasta la realización de su sesión, evitando así la aglomeración de los pacientes en la sala de espera.

En dicho área se realiza la sesión con normalidad, extremando todas las medidas de precaución y portando 
mascarilla quirúrgica tanto personal como pacientes. Si durante la sesión aparecía fiebre, disnea o cualquier otra sospecha clínica en un paciente considerado inicialmente negativo, pasaba a ser dializado en la misma sala pero por una enfermera con el equipamiento de protección individual (EPI) o bien se trasladaba a la zona COVID-19. Como medida de protección añadida a partir del día 7 de abril (día 35) no se sirvieron alimentos durante la sesión. En caso de sospecha en el triaje, antes del inicio de la sesión, el paciente pasaba a la zona destinada a COVID-19 con personal específico y se tomaban las medidas que se describen más adelante.

El equipo de protección que utilizado en el triaje y en la atención a pacientes no sospechosos era una mascarilla quirúrgica y guantes. A partir del 6 de abril (día 34), al comprobar la alta prevalencia de pacientes positivos asintomáticos en el estudio de cribado realizado, se comenzó a utilizar bata desechable, gafas o máscara facial y mascarilla FFP2 para el triaje y también para conexión/desconexión en la zona donde se dializan los pacientes negativos. En esta zona la proporción de personal se ha mantenido con 1 enfermera cada 4 pacientes y 1 auxiliar cada 8 pacientes.

\section{Organización del área de hemodiálisis COVID-19}

En nuestra unidad contábamos con un área física separada con 7 puestos aislados en habitaciones independientes, que se ha habilitado para estos enfermos y que había sido utilizada tiempo atrás para los pacientes con virus hepatitis $C$ positivos.

Inicialmente utilizamos 4 puestos de hemodiálisis que fue necesario aumentar a 7 el día 21 de marzo (día 18), y que a partir del día 32 han pasado a ser 10 y ha sido necesario ocupar parte de la sala común donde hay 24 puestos, dedicando 3 puestos más para los pacientes infectados, garantizándose más de 2 metros de separación entre los pacientes. Además se han marcado con biombos la separación de los pacientes negativos, quedando más de 3 metros entre área de positivos y negativos.

Desde el primer momento se organizaron dos turnos de diálisis con pacientes positivos ambulatorios dejando 1 ó 2 puestos libres para los posibles pacientes detectados en el triaje. Si no aparecían nuevos casos en el triaje, los huecos se ocupaban con pacientes ingresados por COVID-19 que acudían en el día programado en turno de mañana o tarde según situación clínica y puesto disponible. Así, partiendo de la planificación ini- cial ha habido una variación constante en el número de pacientes, siendo necesario un reajuste no sólo diario, sino por turno dado que el número de enfermos cambiaba de momento a momento y su situación de ingreso 0 alta también.

En la zona de atención a pacientes positivos/probables de COVID-19 se distinguía entre personal de atención directa al paciente y personal "espejo", siendo este último el encargado de facilitar material, manejo de historia clínica, preparación de medicación, etc. Las medidas de protección para el personal en esta zona fueron:

- Para el personal "espejo": bata desechable, delantal impermeable, gorro, calzas, mascarilla FFP2, doble guante: uno largo por encima de la bata y uno corto. Se utiliza gafas o máscara facial sólo si fuera necesario acercarse a menos de 2 metros del paciente.

- Para el personal con atención directa a pacientes positivos/probables COVID-19: bata quirúrgica resistente, delantal impermeable, gorro, calzas, mascarilla FFP2, doble guante: uno largo por encima de la bata y uno corto, gafas o máscara facial.

El protocolo de puesta y retirada de EPI para evitar la contaminación incluía cambio de guantes entre pacientes, con higiene de solución hidroalcohólica antes y después del cambio. En esta zona la proporción de personal era distinta al resto de la unidad, para facilitar la atención y disminuir el riesgo de contaminación, pasando a ser de 1 enfermera de atención directa cada 3-4 pacientes, 1 enfermera "espejo" cada 6-8 pacientes y 1 auxiliar cada 5-7 pacientes, que también tiene funciones principalmente de "espejo". La variabilidad de la proporción en esta zona se debía a la adaptación que se tuvo que realizar en función del número de pacientes, preparación de medicación, etc.

Debido a la escasez de Equipos de Protección Individual (EPIs) que vivimos al principio de la pandemia, los profesionales se mantenían con el mismo equipo durante todo el turno de diálisis. Al mejorar el suministro la primera semana de abril, los profesionales cambiaban de rol de atención directa a "espejo" y viceversa, a mitad del turno. En todos los casos se utilizaba una mascarilla quirúrgica por encima de la mascarilla FFP2 para proteger a esta última de contaminación externa que en un principio y también por escasez, se reutilizaban durante tres turnos. 


\section{Manejo del paciente caso probable o diagnóstico positivo}

Los primeros días, ante la sospecha clínica en el triaje o en la sala de hemodiálisis había que avisar a los médicos de medicina interna y el paciente se derivaba al servicio de urgencias al finalizar la sesión para valoración y diagnóstico. Ante el colapso del servicio de urgencias a partir del día 13 de marzo (día 10), se habilitó un circuito de entrada directa para diagnóstico, evaluación de ingreso y tratamiento en el propio servicio de nefrología. Ante la sospecha clínica se procedía a seguir el algoritmo recogido en el Anexo 3.

En nuestro hospital se han ido creando diferentes protocolos de ingreso y tratamiento farmacológico. El primero es del 14 de marzo de 2020 (día 11) que incluía el tratamiento con lopinavir/ritonavir (Kaletra ${ }^{\circledR}$ ) e hidroxicloroquina (Dolquine ${ }^{\circledR}$ ). Se realizó un protocolo más específico, a partir del 24 de marzo (día 21), de cómo manejar a los pacientes en hemodiálisis con COVID-19, con criterios de ingreso y necesidad de tratamiento basado en el protocolo del hospital y del Ministerio de Sanidad, que se ha ido cambiando y adaptando, ya que en el momento actual no existen evidencias sobre la eficacia de ningún tratamiento específico en población general y menos todavía referidos a la población de diálisis (Anexo 4).

En el momento de redactar este artículo son la hidroxicloroquina y la azitromicina los fármacos recomendados en nuestro centro, dependiendo su duración de la situación clínica, y habiéndose añadido en la última semana (día 34) un incremento en las dosis de anticoagulación utilizadas hasta entonces, que hasta este momento no se había indicado de forma sistemática.

En los pacientes COVID-19 en los que se decidía seguimiento ambulatorio, se han repetido pruebas en función del criterio del médico responsable, reconsiderándose la posibilidad de ingreso. Se han realizado evaluaciones presenciales 3 veces por semana, durante las sesiones de hemodiálisis, y los días de no diálisis se ha realizado seguimiento telefónico para evaluar la situación clínica. Hasta la normalización de los parámetros analíticos y radiológicos se ha realizado seguimiento semanal con análisis (bioquímica, hemograma y gasometría venosa) y radiología de tórax. Cuando desparecía la clínica y las exploraciones complementarias eran normales se procedía a repetir el exudado nasal. Si el resultado era negativo, durante 14 días más se continuaba el aislamiento en el domicilio y las sesiones de hemodiálisis se seguían realizando en la zona COVID-19 de la unidad.
Ante el diagnóstico, a todos los pacientes susceptibles clínicamente de irse de alta, se valoraba si podían cumplir con las medidas de aislamiento en el domicilio. En caso de ser así, se les daban instrucciones escritas sobre cómo llevarlo a cabo y se les dispensaban mascarillas quirúrgicas y guantes, para mejorar el aislamiento domiciliario en caso de vivir acompañados.

La alta incidencia de infección en nuestra área $(899,38$ casos por cada 100.000 habitantes) hacía sospechar que habría muchos pacientes con infección asintomática, por lo que propusimos al servicio de medicina preventiva que autorizara la realización de PCR-SARS-CoV-2 a todos los pacientes de la unidad a los que no se les hubiera realizado dicha prueba.

El día 31 de marzo (día 28) comenzamos un cribado mediante la determinación de PCR-SARS-CoV-2. Todos los exudados fueron realizados en el momento del triaje, antes de entrar en la unidad de diálisis y por la misma enfermera.

Si el resultado positivo se obtenía antes de la siguiente sesión de diálisis, se les avisaba telefónicamente para interrogarles sobre la aparición de síntomas clínicos. Si seguían asintomáticos se les informaba de la necesidad de realizar aislamiento domiciliario, y de las recomendaciones sobre cómo acudir a las sesiones de hemodiálisis. En la primera sesión, ya aislados, se realizaba bioquímica de sangre y radiografía de tórax y se decidía individualmente si precisaban o no tratamiento farmacológico.

\section{Seguimiento del personal de la unidad}

El personal sanitario del servicio de nefrología estaba constituido por 9 médicos, y en la unidad de diálisis 22 enfermeras, 11 auxiliares y 2 administrativos (en turnos de mañana y tarde). Se constituyó un circuito en el que ante la aparición de síntomas era necesario ponerse en contacto con el servicio de prevención de riesgos laborales, donde proporcionaban una cita para realización de exudado nasofaríngeo.

En este periodo, se han tomado medidas con el personal administrativo, mediante la colocación de una mampara, y la separación de 1 metro entre esta y el interlocutor además de recomendaciones de prevención. Se han explicado ya los cambios en la protección EPI realizado por el personal auxiliar y de enfermería.

En cuanto al personal facultativo se ha producido una restructuración, ya que 3 de los médicos pasaron a atender a pacientes COVID-19 en el área de hospitalización 
general. En la unidad de diálisis, uno atiende a los pacientes ambulatorios por la mañana y otro por la tarde, y otro se encarga de los ingresos como interconsulta, apoyando a al resto de los médicos que atienden en el hospital a los pacientes COVID-19 y viéndolo solo cuando acude a dializarse.

A modo de síntesis la cronología de los eventos más relevantes acontecidos entre el 3 de marzo y el 3 de abril de 2020 se recogen en la Tabla 1. En el Anexo 4 se muestra la actuación para el manejo del paciente en hemodiálisis con diagnóstico de COVID-19, realizada de acuerdo con las recomendaciones del Ministerio de Sanidad y Consumo y del Hospital Universitario Infanta Leonor $^{11}$.

Tabla 1. Evolución cronológica de los eventos más relevantes.

\begin{tabular}{|c|c|c|}
\hline Día & Fecha & Evento \\
\hline 0 & 3 marzo & $\begin{array}{l}\text { Reorganización de Unidad de hemodiálisis-4 puestos } \\
\text { de diálisis para Covid-19. }\end{array}$ \\
\hline 1 & 4 marzo & Sesión clínica general informativa en el hospital. \\
\hline 1 & 4 marzo & $\begin{array}{l}1^{\circ} \text { caso positivo en el Hospital Universitario Infanta } \\
\text { Leonor. }\end{array}$ \\
\hline 2 & 5 marzo & $\begin{array}{l}\text { Creación del protocolo de actuación en la Unidad de } \\
\text { diálisis. Sesión sobre coronavirus y presentación del } \\
\text { protocolo al personal. }\end{array}$ \\
\hline 3 & 6 marzo & $\begin{array}{l}\text { Entrenamiento en unidad de diálisis para colocación y } \\
\text { retirada de EPIs. }\end{array}$ \\
\hline 6 & 9 marzo & $\begin{array}{l}\text { Entrega de hoja de información a pacientes. Primer } \\
\text { caso de personal. }\end{array}$ \\
\hline 7 & 10 marzo & $\begin{array}{l}\text { Primer paciente detectado (no entra en criterio caso } \\
\text { de ese momento). }\end{array}$ \\
\hline 9 & 12 marzo & Inicio de triaje. \\
\hline 10 & 13 marzo & $\begin{array}{l}\text { Organización independiente en hemodiálisis: pruebas, } \\
\text { diagnóstico y decisión de tratamiento e ingreso. }\end{array}$ \\
\hline 11 & 14 marzo & Fallecimiento primer caso. Primer protocolo. \\
\hline 18 & 21 marzo & 7 puestos de hemodiálisis para Covid-19. \\
\hline 21 & 24 marzo & $\begin{array}{l}\text { Protocolo tratamiento y manejo de paciente en hemo- } \\
\text { diálisis. }\end{array}$ \\
\hline 28 & 31 marzo & Comienzo de screening en pacientes negativos. \\
\hline 32 & 4 abril & 10 puestos de hemodiálisis. \\
\hline 35 & 7 abril & $\begin{array}{l}\text { Se suspende la ingesta de alimentos de los pacientes } \\
\text { en diálisis durante la sesión. }\end{array}$ \\
\hline
\end{tabular}

\section{Tratamiento de los datos}

Se presentan los resultados de las variables cualitativas como valores absolutos y porcentajes, utilizando la media y desviación estándar en las variables cuantitativas. Se utilizó la prueba T de Student para la comparación de medias, considerando significativa una $p<0,05$.

\section{Principios éticos}

El presente trabajo cumple con la ley actual de protección de datos Ley Orgánica 3/2018, de 5 de diciembre, de Protección de Datos Personales y garantía de los derechos digitales.

\section{Resultados}

En el momento de la detección del primer caso en hemodiálisis (10 de marzo) se estaban dializando 90 pacientes en nuestra unidad. Desde ese momento y hasta el día 31 de marzo, un total de 31 pacientes presentaron manifestaciones clínicas de sospecha de infección por COVID-19, realizándose control de PCR SARS-CoV-2, evolución clínica y control radiológico y analítico a todos ellos, resultando un total de 22 pacientes considerados como casos de COVID-19 positivos. A partir del 31 marzo se realizó control PCR SARS-CoV-2 al resto de pacientes asintomáticos de la unidad, resultando un total de 16 pacientes COVID-19 positivos en este grupo, a los que se realizó evolución clínica, control radiológico y analítico. El número total de pacientes $\mathrm{CO}$ VID-19 en nuestra unidad durante este primer mes de seguimiento ha sido de 37 , lo que supone un $41,1 \%$, ver Figura 1.

En la Figura 2 se puede apreciar la evolución diaria de determinaciones PCR-SARS-CoV-2 realizada a todos los pacientes de nuestra unidad.

De los 37 pacientes diagnosticados como COVID-19 positivos, 16 han requerido ingreso hospitalario por criterios clínicos (insuficiencia respiratoria o agravamiento de los patrones radiológicos). Del total de pacientes diagnosticados como COVID-19 positivos, 6 han fallecido durante este primer mes de seguimiento, perteneciendo todos ellos al grupo de pacientes que han requerido ingreso hospitalario.

La media de días de ingreso ha sido $14,7 \pm 5,1$ días en los pacientes que han marchado de alta y $8 \pm 4$ días en los pacientes que finalmente faIlecieron. La estancia hospitalaria ha sido mayor en tres de los pacientes que, por motivo epidemiológico-social y al no poder realizar un adecuado aislamiento domiciliario, han tardado 15-20 días en que la PCRSARS-CoV-2 fuera negativa y poder recibir el alta a domicilio, a pesar de presentar mínima afectación clínica, bioquímica y radiológica. 


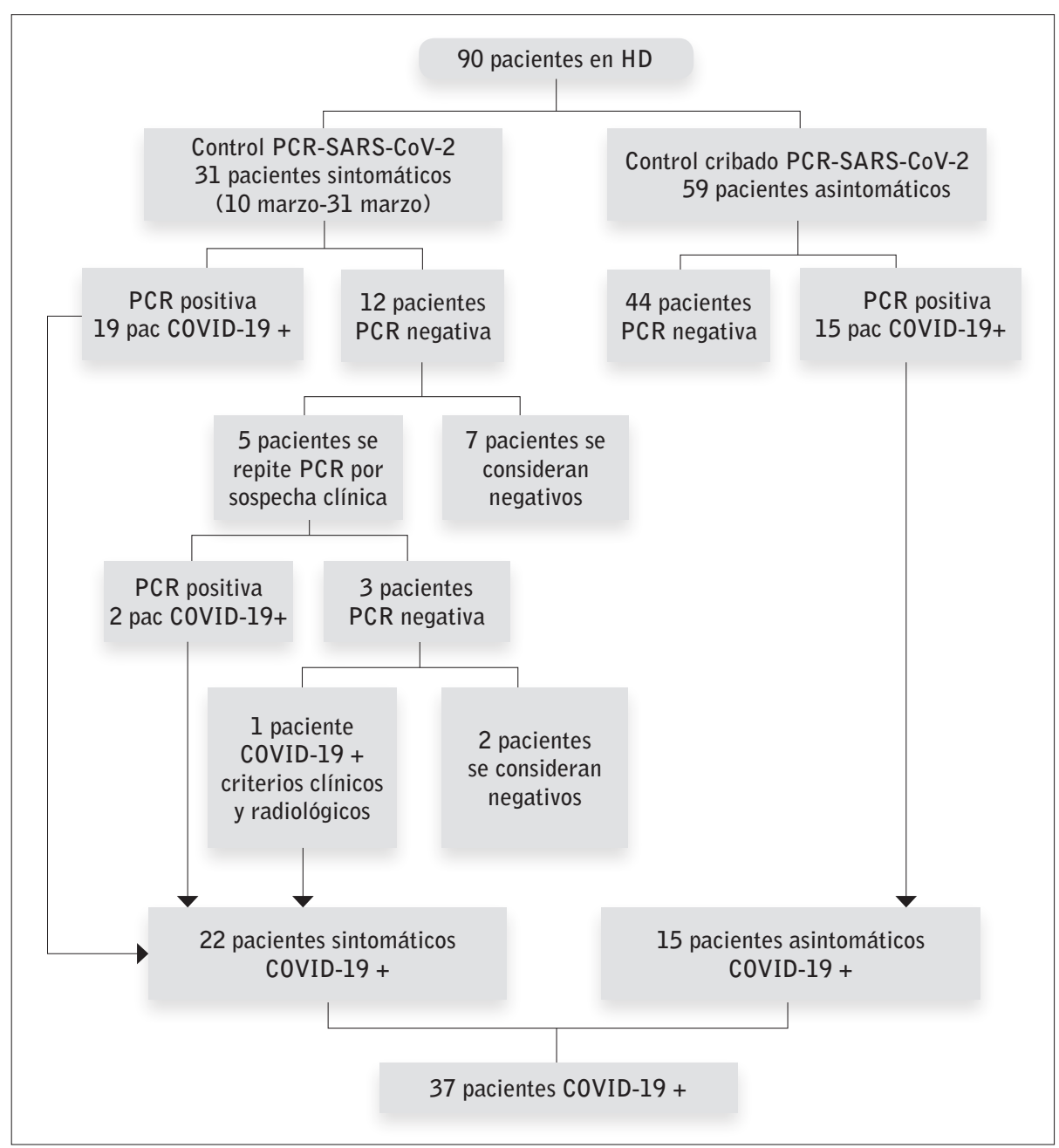

Figura 1. Análisis descriptivo del diagnóstico de infección por COVID-19 en los pacientes en hemodiálisis.

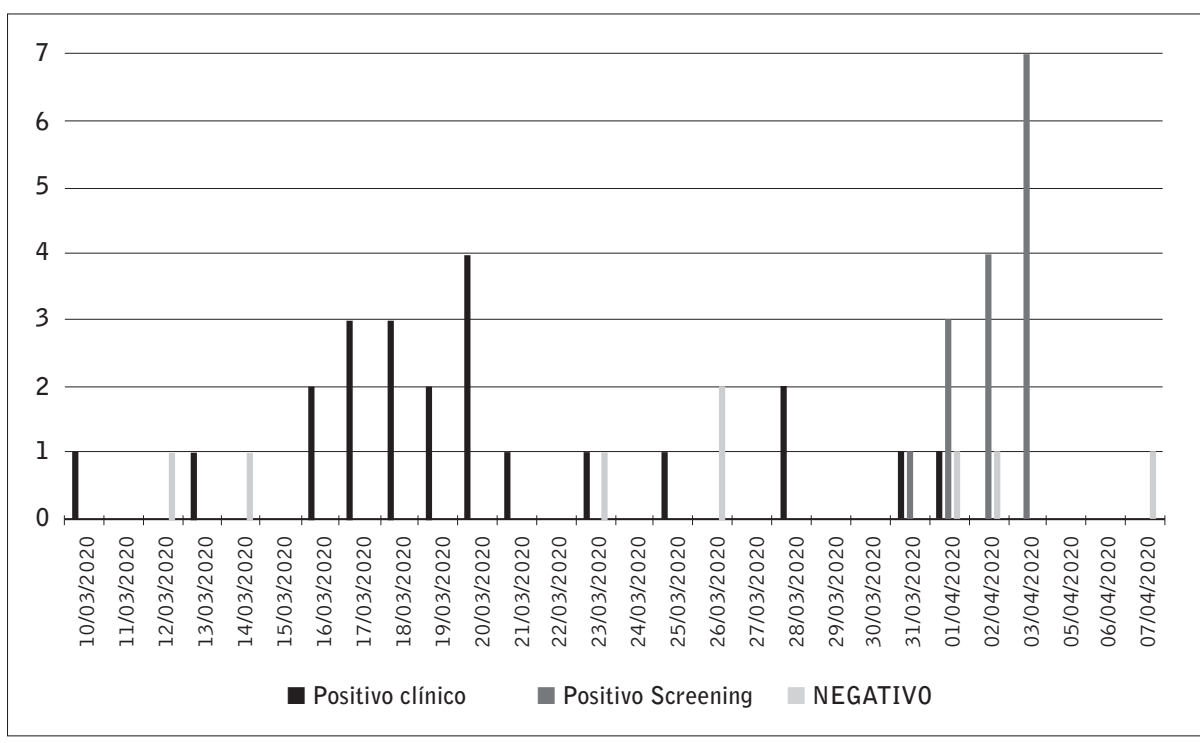

Figura 2. Evolución diaria de PCR-SARS-Covid-2 donde se recogen los datos positivos y negativos por clínica y los positivos detectados por cribado.
En cuanto al tratamiento farmacológico, $6(27,3 \%)$ pacientes han sido tratados con hidroxicloroquina, $6(27,3 \%)$ con lopinavir/ritonavir+hidroxicloroquina, 8 $(36,4 \%)$ con azitromicina+hidroxicloroquina, $1(4,5 \%)$ con azitromicina+ hidroxicloroquina+amoxicilina/clavulánico; y 1 paciente se negó a tratarse.

Las características epidemiológicas, síntomas, valores analíticos e imagen radiológica de los pacientes diagnosticados COVID-19 positivos se recogen en la Tabla 2.

Si se consideran los turnos de las sesiones de hemodiálisis, la tarde ha sido la más afectada con 20 (54\%) pacientes, 9 $(45 \%)$ en el de lunes, miércoles y viernes y 11 (55\%) en el martes, jueves y sábado, que la mañana.

Al comparar los datos entre los grupos de pacientes sintomáticos y el de los pacientes asintomáticos diagnosticados a partir del cribado, se aprecia que la edad, los valores analíticos y los valores de saturación de $\mathrm{O}_{2}$ son similares, mientras que sí hay diferencias en los patrones radiológicos ya que la mayoría de los asintomáticos tienen radiología normal o con más patrones de menor gravedad, lo que se traduce en diferencias en el tratamiento.

Si analizamos la edad media de los pacientes fallecidos frente a los que siguen en evolución, bien de alta o ingresados, vemos como los fallecidos son de mayor edad $80,6 \pm 15,3$ vs. $62,2 \pm 20,6$ años $(p<0,05)$.

\section{Personal de la unidad}

En cuanto a los trabajadores de la unidad, del total de los 44 profesionales, $15(34,1 \%)$ presentaron sintomatología sospechosa de infección COVID-19, realizándose a todos ellos evaluación clínica, determinación PCR-SARS-CoV-2, control analítico y radiológico. Un total de 9 $(20,4 \%)$ profesionales fue diagnosticado de infección COVID-19, precisando uno de ellos ingreso hospitalario por una neu- 
Tabla 2. Datos generales de pacientes Covid-19 sintomáticos/cribado.

\begin{tabular}{|c|c|c|}
\hline Datos generales & PACIENTES SINTOMÁTICOS & PACIENTES ASINTOMÁTICOS \\
\hline Número de pacientes & 22 & 15 \\
\hline Edad en años (media $\pm D E[$ rango]) & $67,2 \pm 20,7[17-100]$ & $68,2 \pm 14,2[44-90]$ \\
\hline \multicolumn{3}{|l|}{ Pacientes según turno de HD (n,\%) } \\
\hline L.X.V. Mañana & $5(22,7 \%)$ & $3(20 \%)$ \\
\hline L.X.V. Tarde & $2(9 \%)$ & $7(46,7 \%)$ \\
\hline M.J.S. Mañana & $3(13,6 \%)$ & $1(6,7 \%)$ \\
\hline M.J.S. Tarde & $9(40,9)$ & $2(13,3 \%)$ \\
\hline Dos días a la semana. Mañana & $2(9 \%)$ & $2(13,3 \%)$ \\
\hline Ingresado agudo. Mañana & $1(4,5 \%)$ & $0(0 \%)$ \\
\hline \multicolumn{3}{|l|}{ Transporte a hemodiálisis (n,\%) } \\
\hline Ambulancia & $16(72,7 \%)$ & $9(60 \%)$ \\
\hline Medios propios & $6(27,3 \%)$ & $6(40 \%)$ \\
\hline \multicolumn{3}{|l|}{ Sintomatología $(n, \%)$} \\
\hline Fiebre presente & $16(72,7 \%)$ & $0(0 \%)$ \\
\hline Tos presente & $10(45,5 \%)$ & $0(0 \%)$ \\
\hline Disnea presente & $3(13,6 \%)$ & $0(0 \%)$ \\
\hline Mialgias presente $(n, \%)$ & $3(13,6 \%)$ & $0(0 \%)$ \\
\hline Dolor faríngeo presente & $1(4,5 \%)$ & $0(0 \%)$ \\
\hline Diarrea presente & $0(0 \%)$ & $0(0 \%)$ \\
\hline \% Saturación 02 (media $\pm D E$ [rango]) & $95,7 \pm 2,6[91-100]$ & $96,3 \pm 1,3$ [94-99] \\
\hline \multicolumn{3}{|l|}{ Datos analíticos (media $\pm D E[$ rango]) } \\
\hline Linfocitos $\left(10^{3} / \mu \mathrm{L}\right)$ & $919( \pm 403,2)[200-1900]$ & $1125( \pm 553,8)[200-2600]$ \\
\hline Dímero-D $(\mu \mathrm{g} / \mathrm{L})$ & $2361,1( \pm 2822)[390-10820]$ & $2598( \pm 2930)[390-12140]$ \\
\hline LDH (U/L) & $205,6( \pm 86,4)[35-372]$ & $155,4( \pm 64,4)[13-247]$ \\
\hline GPT (U/L) & $36,9( \pm 43,2)[10-212]$ & $21,8( \pm 9,6)[9-41]$ \\
\hline GOT (U/L) & $43( \pm 48,1)[10-206]$ & $23,3( \pm 24,5)[7-99]$ \\
\hline Proteína C reactiva $(\mathrm{mg} / \mathrm{L})$ & $46,6( \pm 53,6)[1-173]$ & $12( \pm 10,5)[2-35,5]$ \\
\hline Lactato $(\mathrm{mmol} / \mathrm{L})$ & $1,8( \pm 0,5)[1,35-3,06]$ & $2,3( \pm 0,7)[1,2-3,8]$ \\
\hline \multicolumn{3}{|l|}{ Hallazgos radiológicos $(n, \%)$} \\
\hline Normal & $3(13,6 \%)$ & $8(53,3 \%)$ \\
\hline Opacidad focal & $4(18,2 \%)$ & \\
\hline Tenue opacidad focal & $2(9,1 \%)$ & $3(26,7 \%)$ \\
\hline Patrón intersticial focal o difuso & $4(18,2 \%)$ & $3(20 \%)$ \\
\hline Patrón alveolo-intersticial focal o difuso & $8(36,4 \%)$ & \\
\hline Otros & $1(4,5 \%)$ & \\
\hline
\end{tabular}

DE: desviación estándar; L.X.V.: lunes-miércoles-viernes; M.J.S.: martes-jueves-sábado.

monía grave. La distribución de casos en el personal de la unidad por categorías fue la siguiente:

- Personal administrativo: 1 persona sintomática, presentó PCR-SARS-CoV-2 positiva.

- Médicos: 3 personas sintomáticas, todos PCRSARS-CoV-2 negativa, diagnosticándose 1 persona como COVID-19 positiva por criterios clínicos/ radiológicos.
- Enfermeras: 4 personas sintomáticas, todas PCRSARS-CoV-2 negativa, diagnosticándose 3 de ellas como COVID-19 positivos por criterios clínicos/radiológicos.

- TCAE: 7 personas sintomáticas, 3 con PCR-SARSCoV-2 positiva, diagnosticándose un total de 4 personas COVID-19 positivas ya que 1 fue diagnosticada por criterios clínicos/radiológicos a pesar del resultado de la PCR. 


\section{Discusión}

Nuestro objetivo ha sido describir la experiencia de nuestra unidad de hemodiálisis hospitalaria durante el primer mes de la pandemia ocasionada por SARSCoV-2. El hospital durante la pandemia, al igual que otros centros, se ha transformado convirtiéndose en un hospital COVID-1910-13, y la organización de la asistencia ha sido liderada por el servicio de medicina interna; siguiendo los protocolos de diferentes organizaciones y experiencias publicadas ${ }^{5-6,10}$. Se han formado equipos con protocolos comunes y sesiones diarias en los que las distintas especialidades han estado trabajando juntos. Se ha triplicado el número de camas, se han cerrado quirófanos, consultas, ha aumentado hasta 34 el número de puestos críticos (habitualmente 8 puestos en UCI) habilitándose las diversas unidades quirúrgicas y de reanimación para este fin. El resto de los facultativos se organizaron para cubrir la situación excepcional de la unidad de diálisis, la hospitalización e interconsulta que durante la pandemia las interconsultas han aumentado de forma significativa, realizar Ilamadas telefónicas a los pacientes con enfermedad renal crónica avanzada (ERCA) y de la consulta externa, limitando la asistencia en el hospital a lo estrictamente necesario y realizando los controles de laboratorio imprescindibles en el hospital de día nefrológico. Los pacientes se atienden el mismo día de los análisis y luego el médico responsable se pone en contacto con ellos por teléfono para ajustar el tratamiento según los resultados. Esto concuerda con otras experiencias y con las guías de las sociedades científicas que sugieren minimizar el contacto hospitalario ${ }^{12,13}$.

La enfermería, se ha dedicado casi exclusivamente al tratamiento de hemodiálisis, al pasar también a seguimiento telefónico a los pacientes con ERCA, en diálisis peritoneal y hemodiálisis domiciliaria. Solamente una enfermera permanece en el hospital de día, que debido a la situación se ha restringido a un día a la semana, para atender a aquellos pacientes ERCA que precisaron un mayor seguimiento o para los tratamientos ambulatorios que no pudieron demorarse.

Durante el primer mes de pandemia, hemos pasado del enorme nerviosismo e incertidumbre iniciales de organizando hasta lograr conocer la situación epidemiológica de la misma y detectar pacientes asintomáticos con el objetivo de frenar, en la medida de lo posible, su extensión. Se han presentado las medidas iniciales, la implantación del protocolo, descripción de las características más significativas de los casos y su evolución además los resultado de prevalencia y mortalidad epidemiológico. La falta de experiencia es una constante en todas las publicaciones ${ }^{12-13}$, algunas recogen experiencias emocionales y actitudes de los profesionales destacando el valor del personal sanitario ${ }^{14}$. Es imposible abstraerse del hecho de que es imprescindible el disponer de personal entrenado y de cómo afectaría al trabajo tener que aislarnos, aunque debe ponerse en la balanza la posibilidad de que estemos infectados y, por tanto, seamos vectores de la enfermedad si estamos en contacto con los pacientes ${ }^{15}$.

En el momento de redactar el presente artículo la situación en la unidad sigue siendo compleja, con 31 pacientes COVID-19 positivos, dializándose en los distintos turnos. El último fallecimiento fue el día 2 de abril y los pacientes ingresados/ambulatorios se encuentran en situación estable. Se continúa con idéntica dinámica de triaje, separación y medidas de prevención. Estamos empezando a sacar muestras para determinar qué pacientes tienen PCR SARS-CoV-2 negativa, aunque sobre este aspecto tampoco hay unas directrices claras por lo que mantendrán aislamiento, tanto en domicilio como en la unidad hasta 2 semanas después, cuando se considerarán "negativos", aunque esta definición podría variar si tuviéramos disponibles otros test.

En el momento de la redacción del artículo, ya teníamos algunos pacientes que habían negativizado PCR pero se mantenían en la zona COVID-19 positivos en ese periodo de 14 días. A partir de ese momento, si aparecían casos considerados como probables, y hasta la confirmación de PCR, se aislaban junto con estos pacientes negativizados para poder rentabilizar los espacios y los recursos humanos, debido al elevado número de pacientes que teníamos en aislamiento y para disminuir el posible riesgo de ser contagiados en el caso de que finalmente fueran negativos.

Tenemos una alta prevalencia de infección por C0VID-19, mayor que la referida por otros grupos ${ }^{15-16}$ resaltando que, de ellos, el 40\% eran asintomáticos, lo que aconseja para evitar la propagación del virus, realizar a todos los pacientes un correcto diagnóstico mediante la PCR-SARS-COVID-2 o mejor aún si fuera posible combinar PCR con serologías 7,12 . Esta medida sería deseable que se realizara también al personal, aunque nosotros no hemos podido implementarla como se ha registrado en otros centros ${ }^{4}$. Hemos encontrado una agrupación por turno de los casos, lo que hace pensar en la trasmisión se produce entre enfermos ${ }^{5,12}$ y refuerza la necesidad de un cribado exhaustivo. 
Aunque el porcentaje de ingresos es alto, muchos de los infectados pueden ser atendidos de forma ambulatoria. El porcentaje de muertes es superior a la población general y equivalente al comunicado en el mencionado artículo de Wuhan ${ }^{4}$, aunque aquí la causa fue COVID-19, al contrario que ellos, donde la mayoría murieron de causa cardiovascular. Ninguno ha ingresado en UCI y solo se consideró el ingreso de un paciente de 65 años, pero fue desestimado por presentar patología cardiovascular muy severa.

De los 16 pacientes que han requerido ingreso hospitalario, $9(56,2 \%)$ lo hicieron el mismo día del diagnóstico y el resto en días posteriores por empeoramiento de la clínica. De los pacientes ingresados, 3 mantuvieron una estancia prolongada de ingreso hospitalario por motivos epidemiológicos/sociales, al no poder realizar ambulatoriamente un aislamiento adecuado.

No podemos hacer ninguna afirmación de la eficacia de los diversos tratamientos, ya que se han seguido varios y con distintos criterios. Como reflejan otros autores se debe reflexionar sobre la necesidad urgente de tener protocolos unificados que lleven a conocer qué tratamiento es el mejor $12,15,16$.

A modo de conclusión podemos afirmar que se detectó una elevada prevalencia de COVID-19 positivo en los pacientes de la unidad de diálisis, donde destaca el elevado número de pacientes asintomáticos detectados mediante cribado PCR al total de los pacientes. Algunos profesionales presentaron algún tipo de sintomatología correspondiente con clínica COVID-19, pero se detectaron pocos casos con PCR positiva.

Esta pandemia tiene un coste de vidas y de recursos desconocido en nuestro medio, por lo que es imprescindible aunar esfuerzos asistenciales y de investigación. Esto nos ha obligado a tener una gran flexibilidad en la organización y a mantener al equipo unido y con mucha motivación para poder atender a los pacientes y evitar el colapso del sistema sanitario.

\section{Agradecimientos}

A todo el personal sanitario y administrativo de la Unidad de Diálisis del Hospital Universitario Infanta Leonor y en especial a la Dra. Marta Albalate Ramón por su empuje e iniciativa.
Recibido: 16-04-20

Revisado: 20-04-20

Modificado: 24-04-20

Aceptado: 25-04-20

\section{Bibliografía}

1. Adhanom T. WHO Director-General's opening remarks at the Mission briefing on COVID-19-12 March 2020. Ginebra, Suiza: World Health Organization [consultado 3 abril 2020]. Disponible en: https://www.who.int/dg.

2. Coronavirus disease 2019. World Health Organization. [Consultado 19 marzo 2020]. Disponible en: https://www.who.int/emergencies/diseases/novel-coronavirus-2019.

3. Wu C, Chen X, Cai Y, Xia J, Zhou X, Xu S, et al. Risk Factors Associated With Acute Respiratory Distress Syndrome and Death in Patients With Coronavirus Disease 2019 Pneumonia in Wuhan, China. JAMA Intern Med. 2020 Mar 13. doi: 10.1001/jamainternmed.2020.0994. [En prensa].

4. Zheng $Y$, Xu H, Yang $M$, Zeng $Y$, Chen $H$, Liu R et al. Epidemiological characteristics and clinical features of 32 critical and 67 noncritical cases of COVID-19 in Chengdu. J Clin Virol. 2020 Apr 10;127:104366. doi: 10.1016/j.jcv.2020.10436.

5. American Society of Nephrology Information for Screening and Management of COVID-19 in the Outpatient Dialysis Facility Release [Consultado 4 marzo 2020]. https://www.asn-online.org/ntds/.

6. Basile C, Combe C, Pizzarelli F, Covic A, Davenport $A$, Kanbay $M$ et al. Recommendations for the prevention, mitigation and containment of the emerging SARS-CoV-2 (COVID-19) pandemic in haemodialysis centres. Nephrol Dial Transplant. 2020 Mar 20. pii: gfaa069. doi: 10.1093/ndt/gfaa069. [En prensa].

7. Arenas MD, Villar J, González C, Cao H, Collado $\mathrm{S}$, Crespo M, et al. Manejo de la epidemia por coronavirus SARS-CoV-2 (COVID 19) en unidades de hemodiálisis. Nefrologia. 2020. https://doi.org/10.1016/j.nefro.2020.04.001. 
8. Red de Vigilancia Epidemiológica de la Comunidad de Madrid, Dirección General de Salud Pública, Consejería de Sanidad, Comunidad de Madrid. Infección acumulada por Covid-19 en los municipios y distritos de la Comunidad de Madrid, Madrid Capital. [Consultado el 15 abril 2020]. Disponible en: https://comunidadmadrid.maps.arcgis.com/apps/ PublicInformation/index.html?appid=cdfb6lb3eb3a49c2b990b4fdb4ldfcfe.

9. Garrido H. Mapa del coronavirus: así afecta el Covid-19 a los municipios y distritos de Madrid. Diario El Mundo. 8 abril 2020. [Consultado 15 abril 2020]. Disponible en: https://www.elmundo.es/ madrid/2020/04/08/5e8db4lc2lefa06f278b4570. html.

10. Ma Y, Diao B, Lv X, Zhu J, Liang W, Liu L et al. 2019 novel coronavirus disease in hemodyalisis (HD) patients: report from one HD center in Wuhan, China medrxiv 2020. [Consultado el 23 abr 2020]. Disponible en: https://www.medrxiv.org/content/10. 1101/2020.02.24.20027201v3.

11. Ministerio de Sanidad. Procedimiento de actuación frente a casos de nuevo coronavirus. (Actualización 11.04.2020). http://www.aeemt.com/web/ wp-content/uploads/2020/04/Procedimiento_COVID_19-11042020.pdf.

12. De Sequera-Ortiz $P$, Quiroga-Gili B, De Arriba-De la Fuente $G$, Macía-Heras $M$, Salgueira Lazo $M$, Del Pino y Pino MD. Sociedad Española de Nefrología. Protocolo de actuación ante la epidemia de enfermedad por coronavirus en los pacientes de diálisis y trasplantados renales. Nefrologia 2020; 40(3):253-7.
13. Rombolà G, Heidempergher M, Pedrini L, Farina $M$, Aucella F, Messa P, Brunori G. Practical indications for the prevention and management of SARS-CoV-2 in ambulatory dialysis patients: lessons from the first phase of the epidemics in Lombardy. J Nephrol. 2020 Apr;33(2):193-6.

14. Wang H. Maintenance Hemodialysis and Coronavirus Disease 2019 (COVID-19): Saving Lives With Caution, Care, and Courage. Kidney Med. 2020 Mar 26. doi: 10.1016/j.xkme.2020.03.003.

15. Olynka Vega-Vega, Mauricio Arvizu-Hernánde, José Guillermo Domínguez-Cherit, Juan Sierra-Mader, Ricardo Correa-Rotter. Prevención y control de la infección por coronavirus SARS-CoV-2 (COVID-19) en unidades de hemodiálisis. Salud Pública Mex 2020;62:1-7.

16. Wang X, Liu W, Zhao J, Lu Y, Wang X, Yu C, Hu S, Shen N, Liu W, Sun Z, Li W. Clinical characteristics of 80 hospitalized frontline medical workers infected with COVID-19 in Wuhan, China J Hosp Infect. 2020 Apr 14. pii: S0195-6701(20)30194-8. doi: 10.1016/j.jhin.2020.04.019. 


\section{ANEXO 1. FOLLETO INFORMATIVO SOBRE LOS SÍNTOMAS DE LA INFECCIÓN POR CORONAVIRUS}

Ante la situación generada por la epidemia de infección por este virus y siguiendo las recomendaciones institucionales, queremos darle información sobre la infección por el coronavirus para evitar en lo posible la expansión de la enfermedad y lograr un mejor manejo de la misma.

¿Qué es la infección por el coronavirus?

La infección por el coronavirus es una infección respiratoria causada por un virus similar al de la gripe para el que no estamos vacunados.

¿Cuáles son los síntomas de la infección por el coronavirus?

Los síntomas son similares a los de la gripe, entre los que se incluyen fiebre, síntomas respiratorios, tos y malestar general.

¿Cómo se transmite la infección por el coronavirus?

Se transmite de la misma manera que la gripe, principalmente de persona a persona cuando una persona con gripe tose o estornuda. Las personas también pueden contagiarse al tocar algo que tiene el virus y luego llevarse las manos a la boca o la nariz.

Para evitarse el contagio si una persona tiene síntomas gripales se debe:

- Cubrir nariz y boca con pañuelo desechable al toser o estornudar y proceder a su inmediato descarte en un contenedor de residuos. En los casos de no disponer de pañuelo desechable deberá toser o estornudar en el ángulo formado entre brazo y antebrazo al flexionar el codo. Posteriormente procederá a lavarse las manos con agua y jabón. Puede utilizarse alcohol/gel si no están visiblemente sucias.

- No compartir cepillos dentales, vasos u otros utensilios con la familia o convivientes.

- Lavarse las manos con agua y jabón o gel alcohol con mucha frecuencia.

- Evitar acercarse a menos de 1 metro de las demás personas.

- Evitar los saludos mediante abrazos, besos o estrechamiento de manos.

- Evitar llevarse las manos a la cara.

- Tratar de ventilar los ambientes con aire fresco- abrir las ventanas, sin generar cambios bruscos en las temperaturas. ¿Cómo se puede evitar el contagio y la propagación del virus?

Las medidas de prevención frente al coronavirus consisten básicamente en medidas de higiene personal y medidas de saneamiento ambiental y del entorno.

Como paciente en diálisis le hacemos una serie de recomendaciones adicionales

Normas generales:

1- Mientras dure la situación y hasta nuevo aviso, se evitará viajar con acompañante en el trasporte destinado a los pacientes.

2- Todos los pacientes realizarán higiene de manos antes de entrar en la ambulancia y antes de acceder a la Unidad de hemodiálisis.

Si presenta síntomas:

- Si usted comenzara con síntomas de gripe, o bien en su familia se diagnosticase algún caso de coronavirus, DEBERÁ PONERSE EN CONTACTO CON LA UNIDAD DE DIÁLISIS Y MUY ESPECIALMENTE ANTES DE ACUDIR A LA SESIÓN DE HEMODIÁLISIS. En ese momento se le informará del turno de hemodiálisis y el horario en el que tendrá que acudir. No deberá usar el transporte colectivo con el resto de los enfermos.

- Si es Vd. un paciente en programa de DIALISIS PERITONEAL contactará con la Unidad de Diálisis para concretar una cita para su valoración por los facultativos lo antes posible.

- Si comenzara con síntomas los días que no tiene diálisis, contactarán con los teléfonos que se les ha facilitado, y se le darán las indicaciones oportunas.

Se colocará una mascarilla quirúrgica y extremará la higiene en su domicilio.

En la entrevista telefónica con el facultativo de la Unidad de Diálisis se discernirá si existen datos para pensar que se puede tratar de una infección por COVID19.

Si tras la interrogación telefónica, su médico desestima que se trate de un caso, acudirá a la Unidad de diálisis y se dializará manteniendo las normas establecidas para tratamiento de enfermos con Gripe.

Gracias por su colaboración 


\section{ANEXO 2. ORGANIZACIÓN DE LA UNIDAD DE DIÁLISIS}

\section{En la Unidad de Hemodiálisis:}

- Se activará un triaje preventivo a la llegada de los pacientes.

- Se organizará previamente el traslado de los pacientes sospechosos en ambulancia individual o les traerán en vehículo propio si es posible.

- En estos pacientes se evitará su permanencia en la sala de espera mediante un ajuste del horario de la sesión. Si hay más de un caso, se programarán a estos pacientes en el mismo turno.

- En nuestra Unidad al disponer de 1 sala con habitaciones aisladas físicamente con un circuito de entrada independiente, serán las que se utilizarán para las sesiones de hemodiálisis. En caso de no poder disponer de ellas por cualquier circunstancia, se dializaría al paciente al final de la sala grande de crónicos, fuera de las zonas de paso, con una distancia >2 metros entre paciente y paciente.

- Si se dializan varios pacientes sospechosos o infectados por el COVID-19 se dializarán en puestos próximos y por el mismo personal, y se limitarán las entradas y manipulaciones a las estrictamente necesarias.

- En las habitaciones dedicadas a pacientes sospechosos o infectados se eliminará todo material accesorio que no sea imprescindible para la sesión de diálisis.

- El material que se prevea necesario para la sesión de HD se preparará con anterioridad a la sesión y quedará al lado del monitor de diálisis.

- Se utilizará en la medida de lo posible material desechable.

- El material no desechable como aparatos de TA, saturómetros, bombas de infusión... se limpiará y desinfectará adecuadamente.

- El material que no es imprescindible y no se usa habitualmente quedará fuera del entorno directo del paciente y se administrará al personal médico o de enfermería por personal auxiliar.

- El caso sospechoso no debe concurrir a la sala de lavado de FAV ni a los vestuarios. El paciente deberá realizar en su domicilio un lavado previo del miembro donde tenga la fístula, y completará el procedimiento con desinfección con alcohol en el puesto de diálisis.

- Se indicará "aislamiento de contacto y por gotas", de acuerdo con la información facilitada por el Servicio de Medicina Preventiva del HUIL.

- Se avisará al busca de Medicina Interna .......... para informar del caso y se procederá según sus indicaciones.

- Se reforzará la higiene ambiental con desinfección de la sala previa y posterior a la sesión de diálisis.

- La máquina de hemodiálisis utilizada en un caso sospechoso o confirmado podrá ser empleada a continuación para otro paciente, mediante una adecuada desinfección externa con hipoclorito de sodio. Si bien es deseable se programen estas sesiones si es posible en el último turno.

- No realizar nebulizaciones durante la sesión de hemodiálisis.

- El paciente mantendrá la mascarilla puesta durante toda la sesión.

- Estos pacientes serán atendidos por personal exclusivo, con el EPI correspondiente.

- Estas medidas se mantendrán el tiempo que se estime necesario.

\section{RECOMENDACIONES PARA CASOS SOSPECHOSOS DE PACIENTES EN DIÁLISIS PERITONEAL}

\subsection{En su domicilio}

Idénticas a las del paciente en hemodiálisis.

\subsection{En la Unidad de Diálisis}

- Se evaluará cada caso individualmente y si el paciente no precisa asistencia sanitaria se postpondrá la revisión o procedimiento y se le darán las instrucciones pertinentes al paciente para que permanezca en su domicilio.

- Si precisa asistencia sanitaria se organizará previamente el traslado de los pacientes sospechosos en ambulancia individual o en vehículo propio si es posible.

- En estos pacientes se evitará su permanencia en la sala de espera, de tal forma que a su llegada se le trasladará directamente al box de consulta habilitado específicamente para la atención de estos pacientes.

- Se indicará "aislamiento de contacto y por gotas", mientras dure la atención clínica al paciente en la Unidad de Diálisis, según las medidas que indique el Servicio de Medicina Preventiva del HUIL.

- Se reforzará la higiene ambiental con desinfección de la sala previa y posterior a la atención del paciente.

- El paciente mantendrá la mascarilla puesta durante toda su estancia en la unidad

- Estos pacientes serán atendidos por personal exclusivo, que al acercarse a menos de 2 metros. deberá utilizar máscaras que garanticen su protección. Deberán también contar con protección ocular, bata de mangas largas, gorro y calzas.

- Estas medidas se mantendrán el tiempo que se estime necesario. 


\section{ANEXO 3.}

\section{Circuito sospecha COVID-19. Diálisis y Hospital de Día Onco-Hemato}

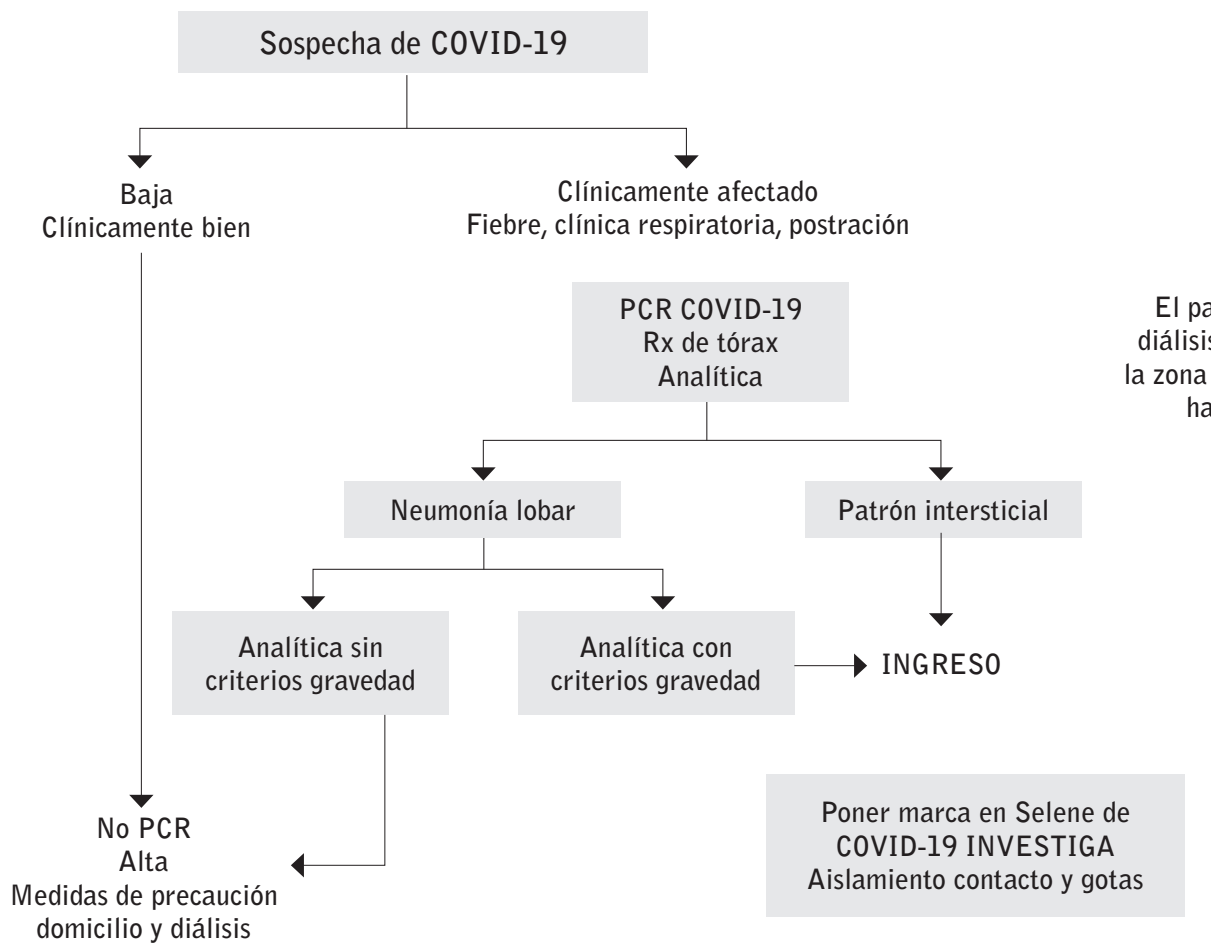

\section{Circuito sospecha COVID-19. Consulta Externa}

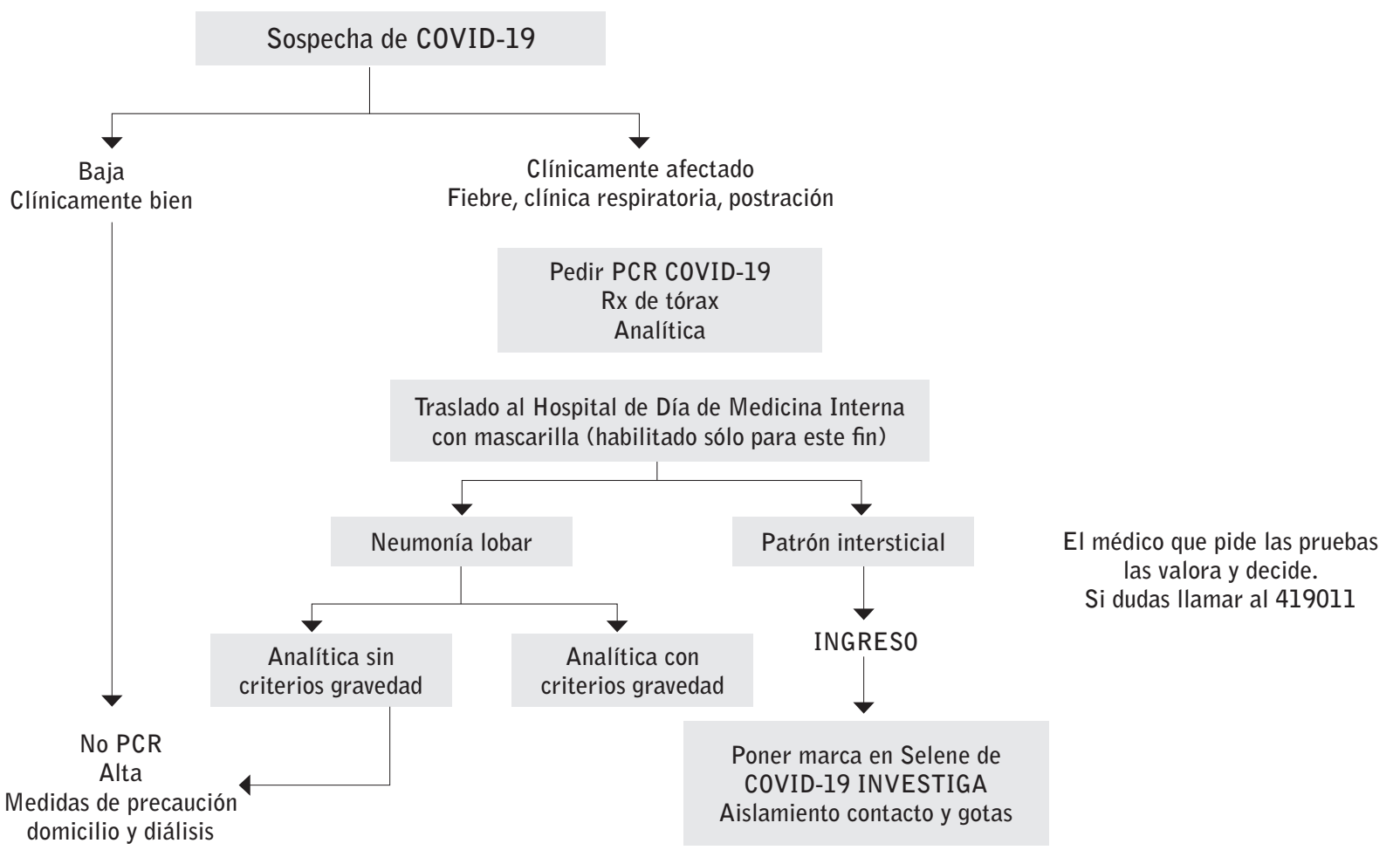




\title{
ANEX0 3. (continuación)
}

\section{Circuito sospecha COVID-19. Hospitalización}

\author{
Sospecha de COVID-19 \\ Llamar a Medicina Interna. 419011
}

\section{ANEX0 4. Criterios de manejo de paciente en hemodiálisis con diagnóstico de Covid-19, realizada de acuerdo con las recomendaciones del Ministerio de Sanidad y Consumo y Hospital Universitario Infanta Leonor}

\section{En todo paciente en diálisis con infección respiratoria o datos clínicos sugerentes de Covid-19:}

- Se efectuará Rx Tórax, análisis y se extraerá PCR para el SAS-Cov-2.

- El personal de enfermería de diálisis se encargará de la extracción de las muestras de sangre para las determinaciones de laboratorio y de la recogida del exudado nasofaríngeo.

\section{Criterios de NO ingreso y vigilancia domiciliaria estrecha}

- Rx normal o con afectación unilobar.

- No insuficiencia respiratoria.

- Posibilidad de realizar aislamiento en su domicilio.

3. Aquellos pacientes subsidiarios de tratamiento ambulatorio se tratarán con:

- Hidroxicloroquina: 2 comprimidos/12 h el primer día y después 1 comprimido cada 12 horas hasta cumplir los 5 días (farmacia hospitalaria).

- Azitromicina: $500 \mathrm{mg} \times 5$ días.

- Amoxicilina-clavulánico 500/125: 1 comprimido cada 12 horas, x 7 días.

\section{El protocolo de seguimiento incluirá:}

a. Rx tórax a las 48-72 horas de la primera. Sucesivas en función de evolución clínica.

b. Laboratorio/48 horas 0, en función de evolución clínica.

c. Valoración por el facultativo de nefrología de la unidad de diálisis en cada sesión de hemodiálisis y, en el caso de paciente en diálisis peritoneal, entrevista telefónica y/o presencial dos días en semana.

\section{CONSIDERACIONES:}

- El paciente en diálisis, y muy especialmente el paciente en hemodiálisis periódica tiene la particularidad de que es atendido por el personal facultativo y de enfermería de la unidad de diálisis tres veces en semana.

- Ante la saturación de camas hospitalarias en el momento actual se plantea la idoneidad de potenciar un seguimiento ambulatorio estrecho en pacientes seleccionados.

- No hay información sobre la actitud a seguir en pacientes asintomáticos con PCR positiva frente al SARS-CoV-2. Dada la ausencia de evidencia clara sobre la efectividad de las estrategias terapéuticas propuestas en este documento, parece razonable no dar tratamiento específico a estos pacientes asintomáticos, con RX normal y sin alteraciones bioquímicas.

Este artículo se distribuye bajo una Licencia Creative Commons Atribución-NoComercial 4.0 Internacional. https://creativecommons.org/licenses/by-nc/4.0/

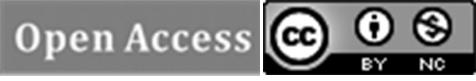

